\title{
PROS Y CONTRAS DE LA INTERVENCIÓN HUMANITARIA EN EL SIGLO XXI
}

\author{
Jean Cadet Odimba on'Etambalako Wetshokonda* \\ Universidad Michoacana de San Nicolás de Hidalgo
}

Fecha de recibido: 28 de enero de 2012

Fecha de aprobación: 12 de junio de 2012

Artículo resultado de Investigación

\section{Resumen}

La globalización económica, la asociación de los Estados y la sociedad de la información, el desarrollo de los medios de transporte, la movilidad humana y los desastres sean naturales o de origen humano, constituyen factores que hacen obligatorios los cambios políticos, sociales o económicos de nuestro tiempo.

Estos cambios generan la necesidad de modificar y adecuar la situación socio-jurídica de los Estados-Naciones, hasta el grado de promover mecanismos jurídicos extraterritoriales con la finalidad de buscar una mejor calidad de vida, procurando garantizar las relaciones interpersonales a través de mecanismos y procesos jurídicos del ámbito internacional que beneficien los intereses generales y arreste la opacidad de las naciones y organizaciones cuando se trate de la cooperación o ayuda humanitaria.

\section{Palabras clave}

Estado, soberanía, principio de no intervención, derecho internacional, Intervención Humanitaria.

\section{PROS AND CONS OF THE HUMANITARIAN INTERVENTION IN THE XXI CENTURY}

\begin{abstract}
Abstrac
The economic globalization, the association of the States and the society of the information, the development of the means of transport, the human mobility and the natural disasters or of human origin, constitute factors that do compulsory the political changes, social or economic of our time.

These changes generate the need to modify and to adapt the situation partner-juridical of the States-Nations, until the degree to promote juridical mechanisms extraterritoriales with the finalidad to look for a better quality of life, procurando guarantee the relations interpersonales through mechanisms and juridical processes in the international field, that benefit the general

Profesor Investigador Titular de tiempo completo y Coordinador General den Centro de Investigaciones Jurídicas y Sociales de la Facultad de Derecho y Ciencias Sociales de la Universidad Michoacana de San Nicolás de Hidalgo. Correo electrónico: jcodimba@hotmail.com
\end{abstract}


interest and arrest the opacity of the nations and organizations in the case of cooperation or humanitarian aid.

\section{Keywords}

State sovereignty, the principle of nonintervention, international law, Humanitarian Intervention.

\section{PROS E CONTRAS DA INTERVENÇÃO HUMANITÁRIA NO SÉCULO XXI}

\section{RESUMO}

A globalização económica, a associação dos estados e a sociedade da informação, desenvolvimento de mobilidade dos transportes, humana e os desastres naturais ou homem, são fatores que tornam obrigatória a política, social ou econômica nosso tempo.

Estas alterações criam a necessidade de modificar e adaptar o sócio-jurídico da Organização das Nações Unidas para promover a grau de extraterritoriais mecanismos legais a fim de buscar uma melhor qualidade de vida, esforçando-se para manter relações através de mecanismos e processos do direito internacional que beneficiem o interesse geral e prender a opacidade das nações e organizações, no caso de cooperação ou ajuda humanitária.

\section{Palavras-chave}

Soberania do Estado, o princípio da não-intervenção, Direito Internacional, Intervenção Humanitária.

\section{INTRODUCCIÓN}

Entre los procesos o mecanismos jurídicos extraterritoriales encontramos los llamados principios de soberanía, derecho de intervención, asistencia humanitaria y la participación en los fenómenos de desastre, los cuales tienden a alterar el orden interno de los Estados involucrados con sus respectivas consecuencias en la política y economía de los mismos. Las secuelas de la intervención provocan cambios no programados $y$ tienen efectos negativos, particularmente en las poblaciones, por lo anterior, merecen una atención especial del derecho Internacional. De ahí se desprende la inquietud de analizar desde un punto de vista jurídico internacional, los beneficios y consecuencias de estos procesos en la humanidad.

Para lograr el objetivo planteado, comenzaremos por analizar el derecho comunitario, desarrollado en el derecho internacional y qué representa un nuevo modelo jurídico para la resolución de los problemas de las sociedades multiculturales.

\section{LA SOBERANÍA DEL ESTADO}

La soberanía en un principio fue vista como un concepto político y posteriormente fue considerada como una noción jurídica. Muchos años después el concepto de soberanía expresaba ausencia de toda subordinación, es decir, una especie de poder supremo que no admitía ningún otro poder por encima de él, ni en concurrencia con él. Esta noción tuvo presencia en el Imperio Romano y fue aceptada por Rousseau y Bodin, los cuales consideraban que la soberanía era un poder absoluto e ilimitado. Pero en la actualidad, la soberanía ha perdido ese sentido absolutista debido a la interacción permanente que existe 
entre los Estados de la Comunidad Mundial, por lo que se considera que se habla ahora como una soberanía relativa.

La soberanía relativa tiene sus antecedentes en la escuela española de derecho internacional, así como en obras destacadas de algunos Iusnaturalistas como son Michoud y Le Fur. Sin embargo, logra su mejor forma de expresión en los procesos de integración de Europa y América Latina. De allí que el concepto de soberanía relativa implique la abnegación de ciertos aspectos de la personalidad internacional de todos los Estados para constituir la comunidad internacional (Gaviria, 1998, p. 48).

La soberanía de un estado puede tener dos modalidades: la soberanía interior y la soberanía exterior. La primera es aquella que es ejercida dentro de los límites del territorio y sobre los individuos residentes en él. Mientras que la segunda o sea la soberanía externa hace referencia a la independencia de un Estado con respecto de otro, se puede decir que es cuando un estado actúa con personalidad jurídica internacional, con todas las facultades y con poder suficiente para adquirir compromisos y pactar obligaciones en el ámbito internacional. Hay autores que consideraban que estas modalidades, sobre todo con respecto a la soberanía externa, no era un análisis muy claro: cuando se refería al derecho que tiene un Estado de oponerse a los demás en su soberanía interna sin que éstos tengan el derecho de intervenir, o bien el derecho que pertenecería al Estado de regular soberanamente sus relaciones con el exterior (Dabin, 1946, p. 5). Sin embargo, en la actualidad dichas modalidades o expresiones de soberanía interna y externa se emplean de manera regular sobre todo en el derecho internacional.

\section{SOBERANÍA Y EL PRINCIPIO DE NO INTERVENCIÓN}

La soberanía tiene una multiplicidad de conceptos, sentidos y alcances, lo que hace que sea difícil de utilizarse, puesto que mucho depende de la interpretación que se haga de su concepto. Cabe mencionar que para los fines de este trabajo no es tan importante adoptar un concepto de soberanía en específico, sino describir de manera general la posible relación entre soberanía y el principio de no intervención.

La soberanía para el derecho internacional es expresada como soberanía relativa. Si los Estados son soberanos se dice que son iguales entre sí, en el sentido que no existe ninguna autoridad jurídica superior y ahí es donde surge esa igualdad entre Estados. Por lo tanto, no puede existir competencia jurisdiccional entre sujetos iguales. Para Michel Virally, la soberanía sigue siendo la base del orden jurídico internacional, presentándose como la garantía jurídica esencial de independencia. De acuerdo a lo anterior la soberanía internacional, se podría definir más bien como una independencia jurídica, debido a que los Estados se determinan libremente sin intervención de terceros estados. Actualmente el concepto de soberanía se encuentra entre dos atributos diametralmente opuestos: entre la independencia y la interdependencia, pero no significa que se deba encuadrar en alguno de ellos sacrificando el otro, sino al contrario, buscar su apoyo y conciliación de ambos atributos en beneficio de la seguridad internacional.

El principio de no intervención de terceros se encuentra íntimamente relacionado con la soberanía del Estado, dado que solamente el derecho internacional puede limitar la acción del Estado. La Carta de las Naciones Unidas en su artículo 2 párrafo 7 establece que, "ninguna disposición de esta Carta autorizará a las Naciones Unidas a intervenir en los asuntos que son esencialmente de la jurisdicción interna de los Estados, ni obligará; a los miembros a someter dichos asuntos a procedimientos de arreglo conforme a la presente Carta..."1. También la Carta de las Naciones Unidas establece en su artículo 52 que, "ninguna disposición de esta Carta se opone a la existencia de acuerdos $\mathrm{u}$

1 Véase Carta de las Naciones Unidas 
organismos regionales cuyo fin sea entender los asuntos relativos al mantenimiento de la paz y la seguridad internacionales y susceptible de acción regional, siempre que dichos acuerdos $\mathrm{u}$ organismos y sus actividades sean compatibles con los principios de las Naciones Unidas". De acuerdo a lo anterior y con relación al principio de no intervención la Carta de la Organización de Estados Americanos (OEA) establece en su artículo 3 inciso e) que,"todo estado tiene derecho a elegir, sin injerencias externas, su sistema político, económico y social y ha organizarse de la forma en que más le convenga y tiene el deber de no intervenir en los asuntos de otro Estado".

En esta misma Carta de la OEA, en relación al derecho de no intervención, se establece en el artículo 19 que: "Ningún Estado o grupo de Estados tienen derecho a intervenir, directa o indirectamente, y sea cual fuere el motivo, en los asuntos internos o externos de cualquier otro. El principio anterior excluye no solamente la fuerza armada, sino también cualquier otra forma de injerencia o de tendencia atentatorias de la personalidad del Estado, de los elementos políticos, económicos y culturales que lo constituyen" ${ }^{2}$. Además en su artículo 20 establece que "Ningún Estado podrá aplicar o estimular medidas coercitivas de carácter económico y político para forzar la voluntad soberana de otro Estado y obtener de este ventajas de cualquier naturaleza". En estos artículos se señala muy puntualmente el deber que tienen los Estados de no intervenir en los asuntos internos de otros Estados.

Continuando con el principio de no intervención, en la OEA se aprobó el 11 de Septiembre del 2001, cuando el terrorismo destruyó las torres Gemelas en Nueva York, en la Carta Democrática Interamericana, en su primer considerando que reconoce que la democracia representativa es indispensable para la estabilidad, la paz y el desarrollo de la Región y que uno de los propósitos de la OEA "es promover y consolidar la democracia representativa dentro del respeto al

2 Véase Carta de la Organización de Estados Americanos principio de no intervención", lo cual se establece en el artículo 2 inciso e).

Para muchos autores el alcance del principio de no intervención es muy discutible, por que no es fácil determinar y sobre todo delimitar el criterio jurídico y el criterio político, para su campo de aplicación. Hans Kelsen, respecto al principio de no intervención establece que el mismo no se encuentra expresamente estipulado en la Carta de las Naciones Unidas, sino más bien se desprende explícitamente del artículo 2 párrafo 4 cuarto, que sostiene que "todo miembro de la organización debe abstenerse de recurrir a la amenaza o al uso de la fuerza contra la integridad territorial o la independencia política de cualquier estado" (Gómez-Robledo, 2000, p. 21).

La doctrina en el ámbito internacional sostiene que un presunto reconocimiento de un derecho general de intervención humanitaria, no es ni legal ni políticamente aceptable. Sin embargo, al excluir este tipo de intervención estatal, no se excluye la posibilidad de una intervención autorizada por el Consejo de Seguridad o por la propia Asamblea General de las Naciones Unidas, siendo ahí donde se discute si la situación amenaza a la Paz y a la Seguridad Internacionales.

Los principios del derecho internacional, durante muchos años han establecido la manera cómo deben darse las relaciones entre los Estados en el ámbito internacional, entre estos principios encontramos el de no intervención en los asuntos internos de otros Estados, la soberanía nacional y la inviolabilidad de las fronteras. Pero en los últimos años la validez teórico-jurídica de estos principios y en especial el de no intervención ha sido poco cuestionada. Claro que la puesta en cuestión del principio puede depender del poder político, económico y militar de quien cuestiona.

Desde hace muchos años han surgido debates álgidos en diferentes temas o doctrinas tal es el caso del positivismo y el jusnaturalismo, los derechos del hombre y los derechos del estado y en el caso de la intervención no ha sido la excepción. En este sentido tenemos el debate entre 
el principio de no intervención y el derecho de intervención. Este debate se basa en determinar cuándo y en qué situaciones es lícito y por tal motivo admisible e incluso justo, que los Estados intervengan en los asuntos de otros Estados (Villagrán, 2006, p. 20).

\section{DERECHO DE INTERVENCIÓN}

La intervención, según Cesar Sepúlveda, es la interferencia no consentida de uno o varios Estados en los asuntos internos o externos de otro, afectando la soberanía y la independencia del Estado intervenido. La intervención se puede realizar utilizando la fuerza o también por medios no violentos, de forma directa o indirecta a través de un tercero, de manera abierta o clandestina, por medio de servicios de espionaje, al interior del territorio o del Estado o tratando de interferir en la conducción de sus relaciones diplomáticas. El Estado que interviene siempre es más poderoso que el Estado que sufre la intervención. Por lo que la intervención es un síntoma de desigualdad que existe en el orden internacional y que constituye un acto ilegitimo de la fuerza (Carpizo, 2004, p. 20).

El concepto de intervención para Socorro Ramírez cuenta con múltiples significados. Ese análisis que la autora hace en su libro "Intervención en los conflictos internos, el caso Colombiano 1994-2003", revela las múltiples modalidades de acción internacional que caracteriza a la intervención, lo cual hace evidente que desde la Segunda Guerra mundial hasta nuestros días, se ha complejizado el concepto de intervención a tal grado que es muy difícil distinguir entre política estatal y política internacional. Por esta razón el concepto de soberanía se vuelve cada vez más vago. Una de esas modalidades es la intervención humanitaria, que en su sentido más amplio autoriza la intervención armada de un Estado en el territorio de otro para poner fin a las violaciones graves y masivas de derechos humanos. Sin embargo, esta modalidad de intervención no tiene cabida en el sistema previsto por la ONU.
La doctrina rechaza la intervención humanitaria en su sentido más restringido, es decir, la intervención armada para salvaguardar a sus propios ciudadanos en otro Estado. A este respecto Jorge Carpizo y otros autores (Bergalli, 2004, p. 27) puntualizan que la injerencia humanitaria, es exactamente lo mismo que la intervención con máscara nueva para tratar de ocultar lo que realmente es; no tienen ningún fundamento jurídico, ni ético y sólo encubre opresión, amagos y carencia de respeto a la soberanía de un Estado.

El discurso base para la intervención de un Estado hacia otro, ha sido por una supuesta necesidad de gestión colectiva para la consolidación de la democracia, el respeto a los derechos humanos, los flujos migratorios, la preservación del medio ambiente y los múltiples tráficos ilegales (Rojas, 2005, p. 95). Tolerar la intervención humanitaria significaría caer en una gran incertidumbre en las relaciones internacionales, pondría en riesgo todo el sistema de seguridad y comportaría manifiestos riesgos de abusos, pues las violaciones de los derechos humanos serían el pretexto para intervenir con otros fines o con otras intenciones (Sandoz, 2004, p. 348). Frente a las crisis humanitarias, algunas intervenciones han dejado la situación peor de como se encontraba antes, tal como lo demuestran los casos de Somalia, Afganistán (1980-1992) y el occidente de África.

El consejo de Seguridad legitima la intervención cuando se presentan las cinco reglas o criterios básicos que legitiman la intervención por razones humanitarias, y debe ser declarada mediante resolución del Consejo de Seguridad y la Asamblea General. Esas reglas básicas son las siguientes: la gravedad del daño o amenaza al Estado o a la seguridad humana; la claridad del propósito tendiente a hacer cesar o a evitar la amenaza; el agotamiento de opciones no militares, es decir, la consideración de la opción militar solo como último recurso; la duración, escala e intensidad de la intervención deben ser proporcionales a la amenaza; y por último, que las consecuencias de la acción de intervención no sean más graves que las consecuencias de la inacción. 
De esa forma, cualquier intervención no podrá ser ejercida por un grupo de Estados en desconocimiento de normas de derecho internacional. Tampoco podrá estar sujeta a los vaivenes de la geopolítica mundial ni a la mediática y coyuntural caridad humanitaria, pocas veces ajena a los juegos de la política interna de los países desde la cual es promovida. La intervención militar debe ser considerada como la última opción, lo cual deja espacios para algunas formas negociadas de intervención institucionalizada, esto es, apoyada en normas del derecho internacional y en las instituciones del país en el cual se ejerce la intervención, siempre bajo la égida del Consejo de Seguridad de las Naciones Unidas. Este nuevo enfoque incluye mecanismos de seguimiento y cumplimiento a los compromisos adquiridos por las partes, a ser ejercidos por ese mismo ente.

La carta de la ONU establece en su artículo 33 que las partes deberán resolver las controversias cuya continuación sea susceptible de poner en riesgo la paz y la seguridad mediante: negociación, mediación, conciliación arbitraje, arreglo judicial, el recurso a organismos regionales y cualquier otro método pacífico. El consejo de seguridad instará a las partes a que solucionen las controversias mediante dichos medios. En caso de que no resuelvan las partes su controversia, el Consejo de Seguridad podrá decidir que medidas que no impliquen el uso de la fuerza armada han de emplearse para hacer efectivas sus decisiones, y podrá instar a que los miembros de las Naciones Unidas apliquen las medidas que pueden ser interrupción total o parcial de las relaciones económicas, de las comunicaciones ferroviarias, marítimas, aéreas, telegráficas, radioeléctricas, y otros medios de comunicación (artículo 41 de la Carta de las Naciones Unidas).

En caso de que las medidas antes mencionadas no sean eficaces, el consejo podrá utilizar las fuerzas aéreas, navales o terrestres, la acción necesaria para mantener la paz (artículo 42 de la Carta de las Naciones Unidas).

\section{EL DERECHO INTERNACIONAL ANTE EL FENÓMENO DE LOS DESASTRES}

Los temas desarrollados anteriormente, de alguna forma justifican la situación y posición que guardan en torno al derecho internacional, como el caso de la soberanía de los estados en la cual ningún otro estado o nación puede invadir la esfera jurídica, sin embargo los cambios de todo orden desde lo político, económico, social y cultural que se manifiestan en cada espacio de la vida pública y privada han exigido a que tanto el principio de soberanía, como el derecho de intervención se redefina su objeto y se adecuen a las necesidades urgentes que surgen y que tienen efectos jurídicos que repercuten y se trasladan al derecho internacional. Todos esos temas que competen al derecho internacional, se han hecho del interés de muchas naciones, sobre todo en los últimos años las naciones que más se han visto afectadas por los desastres naturales y los ocasionados por los propios seres humanos.

Hoy en día, el derecho internacional es de gran importancia en la intervención y participación de los fenómenos que se susciten en los estados partes de los organismos regionales $e$ internacionales, su intervención debe ser sin restricción ni limitaciones tratándose de los desastres, pues en ese caso los intereses que deben salvaguardarse son prioritarios y deben darse las condiciones necesarias por parte del estado receptor y también de la intervención del derecho internacional en tal situación para que en el menor tiempo de inicien las actividades conducentes a contribuir a remediar el fenómeno de los desastres.

Ante el fenómeno de los desastres, en donde las catástrofes mundiales son impredecibles, no respetan nacionalidad, condición social, sexo, raza o religión; sino que llegan en momentos inesperados ocasionado un grave quebranto a las naciones en las que se presentan, quebranto que puede llevarles muchos años para superar. 
Los terremotos, las hambrunas, las sequias, inundaciones, guerras y epidemias, ocasionan severos daños en las naciones que los padecen, muchas veces los países afectados por estos desastres, no están preparados para hacer frente a este tipo de situaciones, de ahí la importancia de la intervención rápida y eficaz del derecho internacional, con el fin de preservar la vida y proteger la dignidad humana. Sin embargo, en muchas ocasiones la intervención de organismos internacionales se ve obstaculizada, por cuestiones de soberanía, los países afectados desconocen o tienen un conocimiento erróneo, sobre el alcance de las normas internacionales al respecto, lo que se complica aun más debido a la existencia de normas obsoletas en esta materia o la escases de éstas.

Al respecto, el Código de conducta: normas de conducta para el Movimiento Internacional de la Cruz Roja y de la Media Luna Roja y las Organizaciones no Gubernamentales en programas motivados por catástrofes, establece en su artículo primero que, "el derecho a recibir y a brindar asistencia humanitaria constituye un principio humanitario fundamental que asiste a todo ciudadano en todo país...", la acción humanitaria internacional debe basarse en principios de neutralidad, por lo que las acciones de intervención en caso de desastres debe estar previamente, consentida por el estado en que se va a actuar.

Existe una gran controversia, respecto a la posición que debe tomar el derecho internacional en casos de desastre, mientras algunos sostienen que en situaciones de emergencia, a mayor apoyo más rápida será la recuperación de una nación; otros afirman que la ayuda en desastres o situaciones de emergencia constituye un peligro para la nación receptora. Por lo que es urgente, la creación de instrumentos internacionales, que reglamente la posición que el derecho internacional debe de tomar frente a las distintas situaciones de desastre, lo anterior en base a la causa originaria del mismo, puesto que es indiscutible que tratándose de desastres naturales el apoyo internacional es trascendental; sin embargo, tratándose de desastre provocados por el hombre, como es el caso de las guerras, el enfoque del derecho internacional debe ser diferente. Y así, para cada situación de desastre la participación del derecho internacional debe estar orientada de diferente forma para coadyuvar eficazmente a la ayuda que se requiera.

\section{INTERVENCIÓN E INJERENCIA INTERNACIONAL}

En cuanto al derecho a la libre determinación y el principio de no intervención están íntimamente ligados y su liga surge a partir del proceso de descolonización, donde la soberanía como atributo del Estado, si bien ya existía, toma toda su fuerza para ser un escudo libertario de los pueblos frente a la intervención de los Estados llamados, en la actualidad, hegemónicos.

Una aproximación al concepto de intervención humanitaria, nos conduce a señalar dos posiciones, por demás antagónicas: la no intervención, que si bien asegura el respecto a la libre determinación de los pueblos, podría a ala vez significar la frustración de fines éticos de asistencia, al perpetuar situaciones de notoria injusticia y miseria. La intervención en estos casos, podría ser una garantía para la realización viable de la autodeterminación de los pueblos.

Una revisión histórica de las intervenciones humanitarias, donde el uso de la fuerza ha sido coloreado por un conflicto de valores $y$ culturas, como se ve en los siguientes ejemplos de intervenciones occidentales y rusas contra los turcos; en Grecia, en 1827; en Siria, en 1860; en Bosnia, Herzegovina y Bulgaria en 1877, y en Bulgaria, Grecia y Serbia en 1913. Hegemónicos y agresores han encontrado la intervención humanitaria como herramienta útil. Hitler usa la fuerza para defender a los alemanes étnicos en el Sudetenland (región de Bohemia Moravia Austria Checoslovaquia), como pretexto para su invasión.

Justificaciones Humanitarias Fueron usadas durante la intervención de India, en 1971, en el Este de Paquistaní; en la intervención de Vietnam, en 1978, contra el Khmer Rouge en Camboya; 
en la intervención de Tanzania de 1979 contra Idi Amín en Uganda y, la intervención francesa, de 1979, contra el régimen de Bokassa, en los República de África Central.

Los Estados occidentales se han enfocado instrumentos diplomáticos o económicos como una variedad de la intervención humanitaria. En los 80, los argumentos humanitarios fueron usados para justificar la imposición se sanciones económicas sobre el régimen de apartheid de Sudáfrica. En los noventas, la intervención militar volvió a la moda, e inicio con la creación de una zona de protección para los kurdos en el norte de Iraq, seguida por operaciones en Somalia y Haití.

Todavía hoy hay fuerte que con autoridad y explícitamente concedan el derecho a la intervención humanitaria.

En la Convención sobre la protección y sanción del crimen de genocidio, que entró en vigor en 1951, se prevé la persecución de los violadores pero no autoriza intervenciones armadas para prevenir o detener el genocidio. Tampoco la Declaración Universal de los Derechos Humanos, o el Convenio Internacional sobre Derechos Civiles y Políticos autorizan la intervención humanitaria.

La intervención de Estado, de manera unilateral $y$ al margen de las instituciones internacionales competentes, para asegurar el someter a un Estado a la justicia internacional ha sido rechazada por la Corte Internacional de Justicia pues dicho argumento ha dado lugar a esconder abusos, así como también puede dar lugar a la imposición de la voluntad de un Estado más fuerte sobre otro débil, lo que conduciría a falsear la administración de la justicia internacional.

El Consejo de Seguridad, de la ONU, es la única instancia facultada para ordenar medidas diversas, pero de carácter ejecutivo, para establecer la paz y la seguridad internacional. Es falso tratar de ligar la estructura interna de la Organización a la estructura de los Estados que la integran. El Consejo de Seguridad es el cuerpo colegiado de decisiones ejecutivas para el mantenimiento y restablecimiento de la paz y seguridad internacional.

De conformidad a varios autores habrá de reconocerse que la intervención humanitaria parece no ser lo mismo que la injerencia humanitaria ${ }^{312}$, la cual pretende, por la fuerza, imponer un modelo económico, social, político o de vida, por parte de un Estado sobre otro que no concede su consentimiento, por lo que viola las forma y el derecho convencionales de relación autónoma entre los Estados establecidos en el terreno internacional (Gros, 2005, p. 209)4.

En cambio, en el caso de la intervención humanitaria se considera la coexistencia de un Derecho Internacional, donde los actores objeto del mismo son los Estados, y, a su lado, un Derecho Internacional que protege los atributos de la dignidad humana, como mínimos, y cuyos sujetos son los individuos, la persona humana.

Cabe mencionar que en la mayoría de los casos de la injerencia, tantas como situaciones complejas presentan las interacciones de los Estados en el ámbito internacional, pero en muy pocas puede identificarse como intervención humanitaria.

Algunos autores identifican, utilizando el término en forma indistinta injerencia e intervención, parece

3 La injerencia humanitaria es la intervención en un Estado soberano por uno o varios Estados u organizaciones internacionales, mediante la fuerza amada y sin su consentimiento con el objetivo de proporcionar a la población civil protección, ante la violación masiva de sus derechos humanos o bien ante situaciones de emergencia derivados de una guerra civil, hambrunas o genocidio entre otras causas. http://www.dostoc.com/docs/39973410/Debate. Consulta el 4 de enero de 2011, 18:24.

4 "El reconocimiento de asistencia humanitaria no genera correlativamente un derecho y mucho menos un deber de intervención por razones humanitarias, del que podrían ser titularse terceros Estados que actúan individual o colectivamente". Gros Espiell, Héctor. Intervención Humanitaria y derecho de Asistencia Humanitaria, UNAM-Comisión Nacional de Derechos Humanos, México. 1995. Pág 209 
más correcto usar el término injerencia en aquellos casos en que la intervención supone el empleo de medios coactivos-cuya manifestación es el uso de la fuerza-. Ello significa que si bien toda injerencia supone una intervención-no toda intervención constituirá especialmente una injerencia.

En este momento viene a la memoria el caso de la exYugoslavía, ¿por qué la tardía intervención de la comunidad internacional?, como también ¿por qué la rápida intervención, en la invasión de Iraq a Kuwait?, -llamada Guerra del Golfo-.

Valga la reflexión, sería porque en el primero se llevaba a cabo una limpieza étnica por parte del grupo hegemónico; $y$, en el segundo estaban en juego intereses económicos petroleros de varios países hegemónico, vale realizar la siguiente razonamiento: fue más importante el usar la fuerza para salvaguardar interese económicos, que para salvar vidas humanas, paradoja que el DIH tiene como agenda pendiente de resolver $y$ vergüenza para la comunidad internacional, ¿̇por su complicidad?. Posteriormente lavada por la Corte Penal Internacional (Sorensen, 1985, p. $394)^{5}$, en el proceso contra Milosevic ${ }^{6}$.

5 La controversia sobre si los juicios por crímenes de guerra, después de la segunda Guerra mundial, constituyeron una aplicación ex post facto de supuestos de dudosa validez y una violación del principio nullum criemen sine lege, parece no tener im 'portancia en vista del hecho de que el concepto de responsabilidad directa del individuo, dentro del derecho internacional en el caso de ciertos crímenes, fue afirmado 'por el consentimiento mutuo de la comunidad de los estados. Ciertos principios mantenidos por juicios de Nuremberg y de Tokio fueron confirmados por la asamblea General en 1946 (Res. 95 (1), 11 de diciembre de 1946). Sorensen, Max. "Manual de Derecho Internacional Público". Editorial Fondo de la Cultura Económica. México, D.F. 1985. Pág.394

6 En la sentencia del 15 de julio de 1999, emitida por la Corte Penal Internacional para la exyugoslavia, se sostiene, en su párrafo 6, que el espíritu de las Convenciones de Ginebra en la lógica del DIH no esta basado en postulados formalistas, por lo que la responsabilidad de un crimen no está en función de la calidad de órgano de un Estado, sino de aquellos que tienen de facto poderes, así como el ejercicio de control sobre los que cometen violaciones al DHI. En su párrafo
En general una intervención para detener el genocidio o la expulsión masiva de grupos étnicos han encontrado un apoyo general, sobre todo porque se consideran que los pueblos que la sufren no tienen ya nada que perder y si una emergencia para enfrentar la desventaja absoluta. Dicha intervención es generalmente aceptada si está claramente delimitada en su propósito para evitar abuso y si observa los principios de legalidad marcados en el capítulo VII de la Carta de la ONU. Un derecho ilimitado que se justifique o funde en los valores a alcanzar es inaceptable, porque la experiencia ha mostrado efectos contraproducentes.

Si las reglas son claras y asumidas por todos, no sería necesario hablar de nuevas reglas para la cooperación internacional, sino de un mundo regido por el Derecho, donde la ONU es el principal pilar de apoyo y la única instancia facultada, como lo es, para determinar los imperativos humanitarios en cuyos casos la soberanía no sería el contra-argumento.

La soberanía no es un derecho absoluto, como el artículo 2(7) de la Carta deja claro en su parte final, y en caso de violaciones persistentes y masivas a los derechos humanos, el Consejo de Seguridad de la ONU estará autorizado, bajo el amparo del artículo 42 de la misma Carta, a hacer uso de fuerzas aéreas, navales o terrestres o implementar cualquier acción que sea necesaria para mantener o restablecer la paz y la seguridad internacionales.

Por su parte, los artículos 55 y 56 de la Carta de ONU contienen una obligación de los Estados miembro a actuar conjunta o separadamente para promover el respeto y la observancia de los derechos humanos y las libertades fundamentales de todos.

Se plantea un problema con las organizaciones regionales que, como muestra la experiencia de

186 , se subraya que es viable fincar la responsabilidad penal individual con base en la culpabilidad persona. 
las acciones emprendidas por la Organización del tratado del Atlántico Norte (OTAN9 en Kosovo (Serrano, 2002, p. 2) ${ }^{7}$, pueden ser contrarias a las determinaciones de la ONU.

Por parte, ninguna Resolución del Consejo de Seguridad (1199 y 1202) autorizaba el uso de la fuerza. Por otra parte, la OTAN no habría necesitado un mandato de la ONU cuando actuaba en legítima defensa bajo el, artículo $V$ de la Carta de la OTAN. El artículo 51 de la Carta de la ONU reconoce que: "nada en la presente Carta debe impedir el inherente derecho de la legítima defensa individualidad o colectiva, como la ONU, y no hay un acuerdo regional que le autorice hacer cumplir la paz y seguridad intencionales bajo el capítulo VIII (artículo 53) de la Carta de la ONU.

Se puede decidir que cada vez con más frecuencia aparecen aquí y allá, partidarios más o menos entusiastas del posible derecho de injerencia por motivaciones de ayuda humanitaria.

Para muchos autores la "intervención humanitaria" no caría dentro del ámbito del artículo $2^{\circ}$, párrafo $4^{\circ}$, de la Carta Naciones Unidas, ya que la injerencia no se estaría llaveando a cabo en contra de la integridad territorial o la independencia política del en cuestión. Lo mismo puede argumentarse en relación con la célebre resolución 2,625 (XXV) del 24 de octubre de 1970, relativo a los principios de derecho intencional que deben guiar las relaciones de cooperación y amistad entre los Estados.

No obstante lo anterior, es difícil esgrimir al argumento de que el derecho positivo avalaría tesis como las antes mencionadas. El recurso

\footnotetext{
"...los famosos acuerdos de Dayton o protocolo de París, celebrados en todo el mundo como un triunfo de la s3ensatez salomónica, en verdad sirvieron para legitimar la limpieza étnica en Bosnia (...) que causo 200 mil muertos. Serrano Figueroa, José Luis. El derecho Humanitario Frente a la realidad bélica de la Globalización. Editorial, Héctor México, D.F. 2002. Pág.2
}

al uso de la fuerza (Serrano, 2002, p. 18) ${ }^{8}$ solo puede "legitimarse" en el marco de la legítima defensa, o dentro del relativo al capitula VII de la Carta de la ONU. Ello es tan cierto que fue precisamente sobre esta última base que el Consejo de Seguridad de Naciones Un idas adoptó en 1991 la resolución 688 relativa a la asistencia humanitaria a la tragedia de las poblaciones kurdas.

\section{OPCIONES DE DIVERSOS TRATADISTAS EN TORNO A LA INJERENCIA INTERNACIONAL HUMANITARIA}

Para juristas como Mario Bettati -uno de los más ardientes defensores de esta particular doctrina de intervención-, la aceleración de la historia, la determinación de algunos estadistas, la Perestroika en ele esta, el auge de la democracia en el Sur, el apoyo decidido dado por la diplomacia francesa y la práctica de la acción humanitaria, todo ello ha contribuido a despojar al pretendido "deber de injerencia", de la connotación un tanto repulsiva que podía poseer años atrás.

A este respecto bien puede aceptarse, dentro de condiciones muy precisas, que en lo sucesivo las violaciones masivas y sistemáticas a los derechos humanos llevadas a a cabo por algún estado, ya no podrán considerarse como un asunto de jurisdicción doméstica, sino como un asunto de jurisdicción internacional.

Al analizar estos puntos el jurista mexicano Jorge Castañeda apuntó que el problema es que:

\footnotetext{
$8 \quad$ "...Cabe hacer la distinción entre dos tipos de fuerzas armadas: las relativas a la seguridad colectiva, prevista en la Carta y bajo el mando directo del, Consejo de Seguridad y las de otro tipo de organizaciones multilaterales, que existen a pesar de que no se contemplan en la Carta, pero que están consensuadas. Ejemplo son los casos azules, contingentes militares colocados bajo la autoridad directa del secretario general de la Organización ...", Serrano Figueroa, José Luis. El Derecho Humanitaria Frente a la realidad bélica de la Globalización. Editorial Porrúa. México, D.F. 2002. Pág. 18
} 
...no sólo se contemplan violaciones graves de derechos humanos, sino que incluso se habla de derecho de injerencia para combatir sistemas políticos nacionales que se alejan del concepto de democracia y libertad europeo o norteamericano. Obviamente, la situación en Europa es distinta que en Latinoamérica en esa materia. Nosotros no podíamos legitimar una intervención de organismos internacionales, y menos aún de otros estados, en estos casos. Creo que México ha tenido toda la razón al limitar la acción internacional legítima sólo de organismos internacionales, a los casos aislados de violaciones masivas y sistemáticas de derechos humanos. En este sentido deberían continuar nuestra acción futura...

Algunos académicos no clasifican las acciones en kosovo como acciones de legítima defensa, porque no hubo un ataque armado conforme al artículo V. Pero argumentar si las acciones en Kosovo son o no legales bajo la ley internacional es perder el problema crucial. Las normas internacionales contienen nociones de conciencias morales que les elevan al nivel de costumbre internacional, para asegurar los mínimos de dignidad y la preservación de la vida, en nuestra opinión se aplicó el ius gens y la costumbre internacional. Encontramos justificación de la intervención de la OTAN en Kosovo, sin esperar la resolución del consejo de Seguridad de la ONU, que como se menciono fue tardía.

Las crisis de los últimos años en lugares como Somalia, Ruanda y los Balcanes han dado lugar a un debate sobre cómo tratar las emergencias humanitarias. Una colección de ensayos, Humanitarian Intervention: ethical, Legal and Political Dilemmas, reunían algunas de las últimas discusiones académicas sobre el tema. Un par de catedráticos de la Universidad Duke, j. L. Holzgrefe y Robert Keohane, han editado este libro en el 2003. En su ensayo, Holzgrefe observa que la Carta de Naciones Unidas prohíbe la injerencia en los domésticos de un estado. Añade, sin embargo, que algunos expertos legales internacionales sostienen que, incluso dentro de la Carta, se permiten la injerencia en determinadas circunstancias.

Éste sería el caso cuando, por ejemplo, hay abusos masivos de los derechos humanos, o una amenaza a la paz de los estados vecinos, debido a un éxodo masivo de refugiados que huyen de la persecución. De hecho, en años recientes el consejo de Seguridad de naciones Unidas ha sancionado la injerencia humanitaria basándose en tales argumentos, en Haití, por ejemplo. No obstante, justificar tal injerencia requiere una autorización específica de las naciones Unidas para no actuar fuera de las disposiciones de la Carta que prohíben la agresión militar, sostiene Holzgrefe.

También precisa que la injerencia humanitaria no es un tema fácil de resolver.

Implica una compleja mezcla de argumentos morales y legales. Además, las razones empíricas sobre las que se puede basar una intervención suelen ser difíciles de establecer con certeza.

Colapso de la soberanía Fernando Tesón, profesor de derecho de una Universidad estatal de Florida, en su ensayo defiende que la ingeniería humanitaria puede justificarse sobre la base del argumento de que la soberanía estatal es un valor instrumental no intrínseco. La tiranía y la anarquía provocan el colapso moral de la soberanía, escribe. Al defender lo que denomina el argumento liberal ala favor de la injerencia, Tesón observaba que la utilización de la fuerza para fines humanitarios conduce a objeciones basadas en el rechazo de la Guerra. Algunas personas comprometidas con los derechos humanos se oponen a la injerencia humanitaria porque concederán que la guerra es un premio, incluso cuando se lleva a cabo con dobles fines. Pero Tesón defendía que algunas veces es moralmente permisible luchar y que, ocasionalmente, luchar es incluso obligatorio. Justificar la agresión para defender los derechos humanos pueden serse según el principio moral del doble efecto, mantenía Tesón. Así, el daño causado por la intervención puede excusarse moralmente cuando tal daño no 
es querido y el fin buscado es normativamente obligado. Al final Tesón apunta; rescatar a los demás será siempre oneroso, pero si negamos el deben moral y el derecho legal de hacerlo, negamos no solo la centralidad de la justicia en los asuntos políticos, sino también la humanidad común que nos une a todos.

La injerencia humanitaria constituye un cambio en las teorías realistas y neoliberales de política internacional, observa Martha Finnemore, profesora asociada en la Universidad George Washington. Esta intervención no se lleva acabo normalmente para ocuparse de los intereses económicos y políticos de un Estado. Un ejemplo de esto es la intervención de Estados Unidos en Somalia, donde no se tenía un interés geopolítico importante. En su libro de 2003, "The Purpose of Intervention: Changnig Beliefs About the Use of Force", Finnemore explicaba que en el pasado ya se dieron acciones humanitarias de algunos Estados. Entre los casos que cita está la supresión de comercio de esclavos en el siglo XIX. Los británicos en particular usaron la fuerza militar para erradicar esta práctica, aunque la acción se limitara a las acciones comerciales, y no a la erradicación forzada de la esclavitud misma. No obstante, con una atención cada vez más creciente a la democracia y a los derechos humanos, el numero de injerencias humanitarias se ha elevado mucho en la pasada década. Tras el aumento de peso dado a los factores humanitarios hay un cierto número de factores.

Primero, ha cambiado la noción de quién puede demandar protección. En el siglo XIX, los Estados poderosos estaban preocupados principalmente por la protección de sus propios ciudadanos. Hoy, se presta más atención a las poblaciones no blancas y no cristianas, y sus problemas tienen un peso mayor.

En segundo lugar, para que se acepte una intervención como legitima ya no es aceptable que sea iniciativa de un único país. Por el contrario, se requiere una acción multilateral, autorizada normalmente por la Naciones Unidas, sostiene Finnemore. El fin de la Guerra Fría hizo más factible obtener el consenso necesario para las operaciones multilaterales, explicándose así el notable aumento de tales acciones en los últimos años, añade Finnemore.

Tercero, los fines han pasado del mero derrocamiento de un gobierno, a la necesidad de instalar un régimen democrático que dé como resultado lideres humanos y justos. Pero las consideraciones humanitarias son todavía solo uno de los factores que actúan en la determinación de la política internacional. La ausencia de determinación para parar la matanza en Ruanda, en 1994, muestra que las exigencias humanitarias compiten con otros intereses de los estados cuando sopesan la decisión de utilizar la fuerza, escribe Finnemore. Otro factor que puede complicar el tema de la injerencia humanitaria es el requisito de que sea multilateral, observa Finnemore. Aunque tiene la ventaja de compartir costes y responsabilidades, hace también difícil la coordinación. Además, la experiencia de algunas operaciones de Naciones Unidas en los últimos años muestra que compartir las decisiones puede debilitar seriamente la efectividad de las acciones militares.

Cuando los derechos humanos son pisoteados David Kennedy, profesor de Derecho en la Universidad de Harvard, planteaba otras advertencias sobre la injerencia humanitaria. En su reciente libro, "The Dark Sides of Virtue: Reassessing International Humanitarism", Kennedy observa que quienes proponen la injerencia encuentran más fácil responsabilizarse de las entradas que de las retiradas, de los éxitos que de los fracasos. Además, advertía de que es necesario prestar mayor atención a las consecuencias negativas de la intervención. Kennedy también advierte que el vocabulario de derechos humanos y el marco institucional de derechos humanos están llenos de contradicciones que no podrían resistir un escrutinio lógico ni un minuto. Parte del libro refleja cómo la creciente tendencia a las intervenciones humanitarias 
ha cambiado la relación entre los activistas humanitarios y los militares. El humanitarismo ya no es algo necesariamente puesto en contra de los estrategas militares.

Por el contrario se ha creado una nueva cooperación. Los humanitaristas han entrado en el mundo del hacer política. Y con esto hay una tendencia hacia un mayor pragmatismo y atención a los factores mundiales. No obstante, este cambio no ha sido aceptado por todos los humanitaristas. Algunos activistas interpretan la ley humanitaria de una forma estricta, excluyendo cualquier uso de la fuerza. Hay algo aparentemente escandalosa en un portaaviones navegando hacia la guerra como realización del humanitarismo internacional, comenta Kennedy. Y la combinación de humanitarismo como estrategia militar y política no es un asunto fácil, añade. Sigue habiendo diferencias entre la más amplia visión humanitaria y el modo en las fuerzas militares juzgan los temas. Por ejemplo, las muertes civiles serán más sentidas por los humanitaristas. El estratega militar puede preguntar cuántas muertes civiles se pueden aceptar para proteger a un soldado. En este punto, el humanitarista es posible que se retire, siendo más conciente de la necesidad de defender la norma de que no se mata a civiles.

El Vaticano esta a favor de la injerencia humanitaria, señala que debería limitarse a situaciones donde resulte evidente que los derechos humanos están siendo pisoteados en una nación.

Decidir cuándo y dónde se presentan estas situaciones no resulta fácil, como muestra el debate académico, en algunas ocasiones la ayuda humanitaria puede esconder otro tipo de intereses, las cuestiones étnicas, morales y religiosas, sostienen opiniones diversas, pero sin embargo consideramos que los seres humanos, tenemos el derecho a vivir en un clima de paz $y$ a que se respete el derecho a la vida en el lugar en donde nos encontremos, pero sin ese lugar es trastocado por cualquier por mínima que sea la amenaza para fracturar la paz o en poner en peligro nuestras vidas, tenemos el derecho a ser protegidos de cualquier amenaza individual o colectiva, trátese de un grupo de liberación nacional, guerrilla, ejercito dentro de un conflicto interno o internacional - el Presidente Felipe Calderón, con su "guerra contra el narco" - vislumbraría las 50 mil muertes que su propio gobierno reconoce y que ahora nos hace potenciales víctimas de la violencia generada-

El tema de los Derechos Humanos cobra vigencia, puesto que el Derecho Humanitario Internacional (DHI) está íntimamente ligado con las injerencias internacionales por motivos humanitarios (Serrano, 2002, p. 151) ${ }^{9}$.

En el 2011 cayó el líder libio Muamart Kadaffi, nuevamente la injerencia no se hizo esperar, ante la crisis suscitada en el Estado libio, el apoyo fue entonces para los rebeldes que luchaban contra el opresor y que se recuerde los medio poco hablaron de la población civil y los problemas que vivió durante el tiempo que duró el enfrentamiento con el régimen líder libio, así como los atropellos sucedidos entre uno y otro bando; en cambio la noticia de la captura y muerte del líder fue ampliamente difundida y celebrada por la comunidad internacional-recuérdese que el líder apoyaba acciones terroristas en el mundo y fue acusado por el derribo de aviones comerciales-.

9 “... ahora las sanciones, las intervenciones, las bombas y las guerras pretenden tornase limpias e inteligentes, Como lo hacen saber permanentemente al público los medios de comunicación y los estrategas. La pretensión de dirigirlas sólo contra los intereses de un Estado, y actualmente contra una persona o grupo de personas, la ha prácticamente privatizado, por lo que ha sido muy debatido si las sanciones establecidas por el Consejo de Seguridad son en realidad un instrumento de justicia o causantes de sufrimientos humanos adicionales, pues su único propósito debe ser evitar, en su instrumentación, el sufrimiento innecesario de terceros, como es el caso de la población civil...". Serrano Figueroa, José Luis. El Derecho Humanitario frente a la realidad bélica de la Globalización. Editorial Porrúa. México, D.F. 2002. Pág. 151 


\section{PROS Y CONTRAS DE LA INTERVENCIÓN INTERNACIONAL HUMANITARIA}

Acciones inmediatas ante violaciones sistemáticas de los Derechos Humanos.

Protección a la población civil en conflictos internos internacionales.

Reconocimiento de DIH por los Estados y grupos insurgentes armados, para la protección de los Derechos Humanos, personas civiles, medio ambiente y monumentos históricos.

\section{PROS Disminución de armamentos.}

El DIH se aplica a todas las partes en conflicto armado, desde el inicio de las hostilidades, durante y aún terminado.

Acciones de ayuda humanitaria en caos de hambrunas.

La instauración de la Corte Penal Internacional, para perseguir a los criminales de guerra o por cometer violaciones a los Derechos Humanos.

\section{CONCLUSIONES}

El respeto de los Estados en el ámbito internacional en cuanto a su soberanía territorial, no puede ser violada, ya sea directa o indirectamente, bajo ningún pretexto. En la actualidad debemos tener claro el concepto de la soberanía como elemento esencial del Estado, pero ya no de forma absoluta sino relativa y flexible, que esté acorde a los objetivos internacionales.

Los intereses de los Estados demandan acciones comunes en diferentes campos como son la política, la economía y la cultura. Por lo que los Estados en la actualidad no pueden mantenerse aislados de otros si quieren lograr un desarrollo, por lo que establecen derechos entre la comunidad internacional para lograr sus objetivos, no solo para el desarrollo de las naciones, sino también para sacar de situaciones de desastres a los estados afectados sea cual fuere.

De acuerdo al desarrollo de este trabajo se concluye que aún no están claros los conceptos del derecho de intervención entre los estudiosos de la materia del Derecho Internacional, e incluso en determinar 
cuándo y en qué situaciones es lícito y por tal motivo, admisible e incluso justo que los Estados intervengan en los asuntos de otros Estados. Por lo que es indispensable revisar los conceptos, así como modificarlos a la realidad en que se vive. La justificación viene a darse para el caso de los desastres, en donde el derecho internacional debe intervenir sin limitaciones para salvaguardar los intereses jurídicos afectados por los desastres en un primer momento y que tal fenómeno no exceda de lo que bien puede evitarse; es necesario también dejar en claro que, hay situaciones en las cuales si debe analizarse ciertas normas internacionales en donde puede interpretarse la invasión de la soberanía de un estado o en todo caso el de intervención, situaciones que se dan ante un fenómeno de desastres como la adopción de niños, lo que implica aplicar normas que no están bien definidas.

Pero el tema central es, dejar en claro la reflexión del papel que debe tomar el derecho internacional ante los fenómenos de desastres sea natural o causados por la fuerza del hombre.

En la actualidad el discurso base para la intervención de un Estado hacia otro, ha sido por una supuesta necesidad de gestión colectiva para la consolidación de la democracia, el respeto a los derechos humanos, los flujos migratorios, la preservación del medio ambiente, los múltiples tráficos ilegales y la lucha contra el terrorismo, donde para esto no existen limitación de fronteras. Aunque las políticas de algunos Estados son extremas en la lucha contra el terrorismo y en el caso de los Derechos Humanos a veces los desprecian y los menoscaban.

\section{BIBLIOGRAFÍA}

Carpizo, Jorge. (2004). Globalización y los principios de Soberanía, autodeterminación y no intervención, Anuario Mexicano de Derecho Internacional, Volumen IV.

Dabin, Jean. (1946). la soberanía del Estado, Doctrina General del Estado, Jus, México.
Ekmekdjian Rivera, Dromi. (1996). Derecho Comunitario régimen del Mercosur, segunda edición, Ediciones ciudad Argentina, Buenos Aires.

Gaviría Liévano, E. (1998). Derecho Internacional Público, Quinta edición, Editorial TEMIS, S. A de Santa Fe de Bogotá-Colombia.

Gómez-Robledo, Verduzco Alonso. (2000). extradición en el Derecho Internacional, aspectos y tendencias relevantes, Segunda edición, Universidad Autónoma de México, Instituto de investigaciones jurídicas, México.

Gómez Robledo-Verduzco Alonso. (2002). El crimen de genocidio en el Derecho Internacional, Boletín Mexicano de Derecho, núm, 105.Pág 16. Disponible en :bibliojuridicas. unam.mx.

Gros Espiell, Héctor. (1995). Intervención Humanitaria y derecho de Asistencia Humanitaria, UNAM-Comisión Nacional de Derechos Humanos, México.

Peraza, Luis. (2006). La jurisdicción Universal: una realidad en constante construcción, Díkaion, Colombia, Año 20, Núm. 15, Universidad de la Sabana, Colombia.

Rojas Rivera, Diana,Marcela. (2005). Intervención en conflictos internos. El caso Colombiano 1994-2003. Análisis Político No 53, enero-Marzo Universidad Nacional de Colombia. Pág. 95-99.

Sandoz, Yves. (2004). "Derechoodeberde injerencia, derecho de asistencia ¿De qué hablamos?", Instituto de investigaciones Jurídicas UNAM. México.

Serrano Figueroa, José Luis. (2002). El Derecho Humanitario frente a la realidad bélica de la Globalización. Editorial Porrúa. México, D.F.

Villagrán Kramer, Francisco. (2005). Los Derechos Humanos y el principio de no intervención, planteamiento sobre reglas esclarecedoras y sanciones por violaciones a los derechos Humanos, Revista interamericana internacional Derechos Humanos, volumen 13. 